\title{
Bovine Mastitis Prevalence, Aetiology, Therapeutics and Control in Tatton Agriculture Park, Egerton University
}

\author{
J.O. Ondiek* and F. Kemboi \\ Egerton University, Department of Animal Science, P.O. Box 536-20115, Egerton, Kenya \\ *Corresponding author
}

\begin{tabular}{|l|}
\hline Ke y w o r d s \\
Antimicrobials, \\
Causative agent, Dairy \\
cow, Milk quality, \\
Sub-clinical mastitis
\end{tabular}

\section{Introduction}

The dairy industry in Kenya contributes $80 \%$ of the milk, and is dominated by small holder farmers (Odero-Waitituh, 2017) who are mostly women. This small-scale dairy sector contributes considerably to reduction of
The study was accomplished to evaluate bovine mastitis therapeutics and control in Tatton Agriculture Park (TAP), Egerton University. Causative agents were investigated through culture and identification then subjected to commonly used antimicrobials to determine their sensitivity hence identify drug of choice. A total of 41 dairy cows or 164 quarters were sampled from TAP. Of all the samples, 34.1\% were California Mastitis Test (CMT) positive for sub-clinical mastitis while $82.9 \%$ yielded bacterial growths. When cultured $21.4 \%$ of the CMT positive were without growths (false positive) while $85.2 \%$ of those that tested CMT negative yielded bacterial growths (false negative). The most prevalent bacterial species were Staphylococcus aureus (58. 8\%). The CMT was not a fully reliable test for detection of sub-clinical mastitis, therefore, should be accompanied by a bacteriological test for accurate diagnosis. The study showed that the causative organisms were most sensitive to Tetracycline, Gentamycin, Enrofloxacin, Sulfamethoxazole, Ceftifour and Streptomycin, with the least effective drugs being Ampicillin, Neomycin and Cloxacillin. Most drugs used on the farm were Terrexine, Intramammary tubes (multiject), Adamycin, Penstrep, and Neomycin. The incidence rate of mastitis in TAP was at $82.9 \%$. The specific causative agents were Staphylococcus aureus, Streptococcus agalacteae, and Escherichia coli. Staphylococcus ssp accounted for $58.8 \%$ of the mastitis cases while Streptococcus ssp accounted for $11.8 \%$, and Escherichia coli accounted for $8.9 \%$. Mixed infections of Staphylococcus ssp, Streptococcus ssp and Escherichia coli accounted for $20.5 \%$ of the cases of mastitis infection. It is concluded that the most effective method for the prevention of mastitis is through the establishment of good husbandry practices, sanitation, sound milking procedures, including post-milking, teat dipping and treatment during the non-lactating period and culling of chronically infected cows. 
Different causal organisms including bacteria, mycoplasma, fungi and yeasts are the major pathogens and these are usually distributed in the environment. Some of the particular organisms are Streptococci (Streptococcus agalactiae, Streptococcus dysgalactiae, Streptococcus uberis); Staphylococci (Staphylococcus aureus); Coliforms (Escherichia coli, Klebsiella pneumonia, Pseudomonas aeruginosa); Mycoplasmas, Leptospiras, Macrococci, Corynebacterium (Corynebacterium pyogenes), Mycobacterium and Yeast and fungi. Most mastitis cases are due to defective management -poor milking procedures, overstocking, chilling of the udder, poor use of milking machine or the change from hand to machine milking (Current concepts of Bovine mastitis, 1996).

Mastitis presents in two forms depending on presence or absence of clinical signs, as clinical mastitis or sub-clinical mastitis. Commonly used methods of assessing impacts of mastitis in Kenya are observational structures and clinical trials. The latter are based on random allocation of animals or farms provide a better level of process in testing alternative control methods than do observational method when groups are selfselected by a farmer or investigator and that's more susceptible to confounding effects (Madison, 1999).

Milk production in Kenya in the showing a wide range of $1300 \mathrm{Kgs}$ to $4000 \mathrm{Kgs}$ per cow per year has been reported (Peeler and Omore 1997; Omore et al., 1999), but this changes with the level of intensification and agroecological areas (Muia et al., 2011), with the highest being $4575 \mathrm{~kg} / \mathrm{cow} / \mathrm{year}$ in high potential areas (Mugambi et al., 2015).

The yield per animal is low as equated to worlds best of 9000 litres per year (Techno serve, 2008) but it can be enhanced with noble management (USAID/GoK 2009).
Mastitis is a worldwide problem affecting animal health, quality of milk (Ondiek et al., 2018) and economics of milk production, including huge financial losses (Sharma et al., 2012). Probable losses from decreased milk yield alone amount to well over $\$ 1$ billion yearly, and when all other expenses are computed, it transforms to approximately $\$ 185$ per cow (Philpot and Nickerson, 2000).

Bovine mastitis leads to varying degrees of economic losses (Van Soest et al., 2016; Hogeveen and Van Der Voort, 2017; Aghamohammadi et al., 2018). The normal case of clinical mastitis results in an entire economic monetary value of $\$ 444$, with $\$ 128$ in direct costs and $\$ 316$ in indirect costs. Direct costs comprised diagnostics (\$10), therapeutics (\$36), non-saleable milk (\$25), veterinary service $(\$ 4)$, labor $(\$ 21)$, and death loss (\$32). Indirect costs included succeeding milk production loss $(\$ 125)$, premature culling and replacement cost (\$182), and future reproductive cost (\$9) (Rollin et al., 2015).

The loss is in addition to developing of resistance to antibiotics (Saini et al., 2012, Oliver and Murinda, 2012) particularly penicillin, pirlimycin and florfenicol. ampicillin, cefoxitin, chloramphenicol, trimethoprim-sulfamethoxazole combination, sulfisoxazole, streptomycin and kanamycin tetracycline and sulfisoxazole; cloxacillin, penicillin-novobiocin combination, and cephapirin used for dry cow therapy, and ceftiofur used in lactating cow therapy applied as systemically or intramammary infusion (Saini et al., 2013). Some strains of microorganisms may displayresistance to several drugs, even multidrug resistance (Yoshimura et al., 2002; Nunes et al., 2007; Oliviera et al., 2012; Fernandes et al., 2016).

High mastitis prevalence $34-82 \%$ reported by Ondiek et al., (2013) is due to the absence of surveillance on the control program, poor 
hygiene during milking and infrequent preventive measures. Since mastitis prevalence is normally high during the long rainy season and in dry cows, there is a need for control and prevention of mastitis at this particular time. This study was set up to find the best management practices for control of mastitis in TAP, and investigate the incidence rate, the specific causative agents and effective drugs for mastitis treatment.

\section{Materials and Methods}

\section{Milk sample collection}

Sterile 100ml Boujou bottles were labeled prior to sampling. Hands were washed with soap under running tap water, and teats were washed in sanitizing solution, dried with towels, and the first two squirts of milk discarded from each teat before sampling.

The sterile Boujou bottle was opened under the lease and held at an angle to prevent any foreign material from falling into the openings. Two squirts of milk were collected from each quarter beginning from the closest quarters and working towards the ones furthest away. The Boujou bottle was then closed before removing it from beneath the teats. Samples were refrigerated until the time of analysis in the laboratory.

\section{Culturing of samples}

Bunsen burner was used to sterilize the air around the operating area and to sterilize the inoculation wire loops. The inoculation loop was cooled using prepared solidified agar and the bottle containing the sample was then gently swirled to mix the milk. The Boujou bottle was opened and a loopful of milk taken from each sample bottle and streaking done for dilution. For each sample, inoculation was done on both Nutrient and MacConkey agar, labeled and incubated at $37^{\circ} \mathrm{C}$ for 24 hours to allow the growth of bacterial colonies present in the milk samples.

\section{Identification of isolates}

Bacterial colonies were identified according to colony characteristics and cultural characteristics which were reported as heavy pure growth, heavy mixed growth, scanty growth, moderate mixed or no growth.

Gram staining was carried out as follows: Bacterial smear was made on a clean glass slide. It was then air dried and fixed by passing it over a flame 3 times, stained with crystal violet for 30 seconds, and washed with plenty of distilled water. Lugol's iodine was poured over the slide for 30 seconds (a mordant), then the slide was washed with acetone to decolorize it, counterstained with carbolfuchsin stain for 30 seconds, then washed and dried. It was examined using x100 oil immersion objective lens where, grampositive organism appeared blue or purple and gram-negative was pink or red (Black and Black, 1999).

\section{Sensitivity test}

To evaluate the antimicrobial resistance a wire loop was heated, cooled and a pure colony picked and streaked in a nutrient agar plate while a mixed culture was also picked and platted on a different plate.

These plates were incubated at $37^{\circ} \mathrm{C}$ for 24 hours after which they were observed for growths and inhibition zones. To determine the most effective drugs to clear all cases of mastitis infections caused by microbes the following antimicrobial agents were used; Tetracycline, Gentamycin, Enrofloxacin, Sulfamethoxazole, Ceftifour, Streptomycin, Ampicillin, Neomycin and Cloxacillin. The percentage of sensitivity to pathogens was also computed and presented in a table 4 . 


\section{Results and Discussion}

The CMT test revealed a positive prevalence of 14 cows or $34.1 \%$ cases while 27 cows or $65.9 \%$ of the 41 cows were negative. Of the 27 CMT negative cases, 23 or $85.2 \%$ had growths and only $11.1 \%$ did not result to growths. However, of the CMT positive cases, $21.4 \%$ were false positive and had no growth whereas $78.6 \%$ were true positive. A total of $64.4 \%$ of the samples showed false results of either False _ or False + (Table 1 and 2).

The bacterial pathogens isolates associated with mastitis cases in TAP include: Staphylococcus ssp, Streptococcus ssp, mixed infections (Staphylococcus ssp, Streptococcus ssp and Escherichia coli) and Escherichia coli (Table 3).

Therapeutic management of the milking cows is done by administration of anti-mastitis drugs either by injection or intramammary infusion. The drugs of choice include Tetracycline, Gentamycin, Enrofloxacin, Sulfamethoxazole, Ceftifour and Streptomycin (Table 4).

CMT is an indirect cow-side chemical test for estimating somatic cell numbers. The chemical reagents rapture the cell thereby releasing DNA responsible for the gel formation and viscosity (Schalm et al., 1971). The ability of the test to predict the presence of bacteria depends on the level of the somatic cell in the quarter. According to the results stipulated in the table 2 it shows that, out of 41 samples, 14 were CMT positive of which $21.4 \%$ were a false positive. Of the $27 \mathrm{CMT}$ negative samples, $85.2 \%$ were a false negative. They may have resulted from an experimental error and the unreliability of CMT reagent as an indicator of the presence of bacteria. Out of the 41 samples, 34 samples showed growth which represents $82.9 \%$ of the cases analyzed. Therefore, CMT cases should be accompanied with bacterial isolation for effective decisions on control and treatment of sub-clinical mastitis. The bacterial isolates, in this case, are important pathogens associated with mastitis in dairy production (Wilson et al., 1995). Staphylococcus ssp account for $58.8 \%$ of the mastitis cases in Tatton Agriculture Park (TAP) while Streptococcus ssp accounts for $11.8 \%$ and mixed infections of Staphylococcus ssp, Streptococcus ssp and E. coli account for $20.5 \%$. E. coli accounts for $8.9 \%$ of the cases of infections.

There is a need to determine efficient tool to use specific antibiotic which can efficiently stop and control bovine mastitis in dairy animals (Hossain et al., 2017). Bovine mastitis is caused by numerous forms of gram positive and negative microbes and consist of infectious pathogens, environmental pathogens, minor and uncommon pathogens which can be treated by applying specific and selective antibiotics (Radostits et al., 2000). The sensitivity in table 4 shows that the most effective drugs to clear all cases of mastitis infections are; Tetracycline, Gentamycin, Enrofloxacin, Sulfamethoxazole, Ceftifour and Streptomycin, the least effective drugs being Ampicillin, Neomycin and Cloxacillin. Gram negative pathogens were reported to be more sensitive to enrofloxacin and gentamicin and to a lesser extent sensitive to ampicillin and penicillin (Karthikeyan, 2003) which backed up the present outcomes in both the antibiotic sensitivity tests. Gram positive bacteria were more sensitive to Enrofloxacin, Sulfamethoxazole, Ceftifour, Cloxacillin. Penicillin, amoxicilin and Streptomycin, and less sensitiveto Ampicillin and Neomycin. The various drug resistance between the cultures involved in mastitis has also been shown by other researchers (Yoshimura et al., 2002; Nunes et al., 2007; Saini et al., 2012; Oliver and Murinda, 2012; Oliviera et al., 2012; Saini et al., 2013; El-Hamid et al., 2016; Gomes et al., 2016). 
Table.1 Cows, CMT reaction, cultures and microorganism identification in TAP

\begin{tabular}{|c|c|c|c|c|c|}
\hline No. & Cow & CMT & $\begin{array}{l}\text { Growth/No } \\
\text { growth }\end{array}$ & $\begin{array}{l}\text { Result } \\
\text { Interpretation }\end{array}$ & Specific Microorganisms \\
\hline 1 & Patricia 13 & - & Growth & False & Staphylococcus \\
\hline 2 & Terry & - & Growth & False _ & Staphylococcus, E. coli \\
\hline 3 & Maiden 57 & - & Growth & False _ & Staphylococcus \\
\hline 4 & Maiden 59 & - & Growth & False_ & Staphylococcus \\
\hline 5 & Taveta 5 & - & Growth & False _ & Streptococcus, Staphylococcus \\
\hline 6 & Buttercup 15 & - & Growth & False_ & Staphylococcus \\
\hline 7 & Ngong 22 & - & Growth & False _ & E. coli \\
\hline 8 & Lucy 19 & - & Growth & False _ & Streptococcus, Staphylococcus \\
\hline 9 & Susan12 & - & Growth & False _ & Staphylococcus \\
\hline 10 & Susan 11 & - & Growth & False_- & Streptococcus, Staphylococcus \\
\hline 11 & Buttercup 17 & - & Growth & False _ & Staphylococcus \\
\hline 12 & Maiden 67 & - & Growth & False _ & Streptococcus \\
\hline 13 & Bushbaby & - & Growth & False _ & Staphylococcus \\
\hline 14 & Buttercup 16 & - & Growth & False _ & Staphylococcus \\
\hline 15 & Maiden 59 & - & Growth & False _ & Staphylococcus \\
\hline 16 & Maiden 60 & - & Growth & False _ & Staphylococcus \\
\hline 17 & Kilo 18 & - & Growth & False _ & Streptococcus \\
\hline 18 & Panzi 20 & - & Growth & False _ & Staphylococcus \\
\hline 19 & Patricia 17 & - & Growth & False _ & Staphylococcus \\
\hline 20 & Janet 26 & - & Growth & False _ & Streptococcus \\
\hline 21 & Ngong 24 & - & Growth & False _ & Staphylococcus \\
\hline 22 & Waterbuck & - & Growth & False_ & Streptococcus, Staphylococcus \\
\hline 23 & Maiden 64 & - & Growth & False_ & Staphylococcus \\
\hline 24 & Betty & + & No growth & False + & - \\
\hline 25 & Tembo 3 & + & No growth & False + & - \\
\hline 26 & Maiden 65 & + & No growth & False + & - \\
\hline 27 & Maiden 58 & - & No growth & True_ & - \\
\hline 28 & Janet & - & No growth & True_ & - \\
\hline 29 & Maiden 70 & - & No growth & True _ & - \\
\hline 30 & Julia 6 & - & No growth & True_ & - \\
\hline 31 & Tembo 5 & + & Growth & True + & Streptococcus Staphylococcus \\
\hline 32 & Maiden 66 & + & Growth & True + & Staphylococcus \\
\hline 33 & Ngong 17 & + & Growth & True + & E. coli \\
\hline 34 & Tembo 6 & + & Growth & True + & Staphylococcus \\
\hline 35 & Kilo 20 & + & Growth & True + & Staphylococcus \\
\hline 36 & Ruth & + & Growth & True + & Streptococcus, E. coli \\
\hline 37 & Patricia 14 & + & Growth & True + & Streptococcus \\
\hline 38 & Patricia 16 & + & Growth & True + & Staphylococcus \\
\hline 39 & Maiden 69 & + & Growth & True + & Staphylococcus \\
\hline 40 & Lucy 19 & + & Growth & True + & E. coli \\
\hline 41 & Kilo 20 & + & Growth & True + & Staphylococcus \\
\hline
\end{tabular}

Key: CMT positive (+) gel formation; CMT negative (-) no visible change 
Table.2 Results of bacterial growth and \% distribution

\begin{tabular}{|l|l|l|l|l|}
\hline Test used & No. of samples & $\%$ of growth & $\%$ of no growth & $\begin{array}{l}\% \text { of total } \\
\text { samples }\end{array}$ \\
\hline CMT positive & 14 & $11(78.6)$ & $3(21.4)$ & 34.1 \\
\hline CMT negative & 27 & $23(85.2)$ & $4(14.8)$ & 65.9 \\
\hline Total & 41 & $34(82.9)$ & $7(17.1)$ & 100.0 \\
\hline
\end{tabular}

Table.3 Mastitis microorganism prevalence (\%) in TAP

\begin{tabular}{l} 
Microorganisms \\
Staphylococcus spp \\
\hline Mixed (Staphylococcus spp, E. coli \& Streptococcus spp) \\
\hline Streptococcus spp \\
\hline Escherichia coli
\end{tabular}

Total

\begin{tabular}{|l|l|}
\hline Number $(\mathbf{n})$ & $\%$ prevalence \\
\hline 20 & 58.8 \\
\hline 7 & 20.5 \\
\hline 4 & 11.8 \\
\hline 3 & 8.90 \\
\hline 34 & 100 \\
\hline
\end{tabular}

Table.4 Antibiotic sensitivity (\%) of different microbial pathogens to different groups of antibiotics

\begin{tabular}{|l|}
\multicolumn{1}{|c|}{ Antibiotics } \\
\hline Penicillin \\
\hline Ampicillin \\
\hline Amoxicillin \\
\hline Tetracycline \\
\hline Gentamicin \\
\hline Neomycin \\
\hline Cloxacillin \\
\hline Streptomycin \\
\hline Enrofloxacin \\
\hline Erythromycin \\
\hline Ceftifour \\
\hline Sulfamethoxazole \\
\hline
\end{tabular}

\begin{tabular}{|l|l|l|}
\hline Percentage of sensitivity to pathogens & \\
\hline S. aureus & S. agalactiae & E. coli \\
\hline 86.8 & 100 & 4 \\
\hline 8.33 & 20 & - \\
\hline 78.9 & 100 & 18 \\
\hline 70.4 & 60 & 40 \\
\hline 97.8 & 40 & 94.4 \\
\hline 28.0 & 0 & 41 \\
\hline 92.1 & 100 & 2 \\
\hline 71.1 & 66.67 & 84 \\
\hline 97.4 & 100 & 100 \\
\hline 51.8 & 80 & 20 \\
\hline 94.7 & 100 & 100 \\
\hline 99.3 & 98.6 & 88.9 \\
\hline
\end{tabular}

According to TAP records, mastitis remains a bother to the farm, since it has raised the cost of production through treatment and discarding of milk. It is associated more with the environment because of the way milking and milking procedures are conducted. Most cases are reported during the drying off period, heavy rains, during shortages of waters for cleaning parlor and equipment, incomplete milking due to lack of experience by workers and the unhygienic situation in the farm. Once there is a positive case in the farm, they do diagnostic tests i.e. use strip cup and CMT kit, and then take a sample for culture and sensitivity in the laboratory.

After milking the workers forget to put the teats into teat dip thus encouraging 
multiplication of bacteria hence relapse of mastitis especially at late lactation.

Some of the most commonly affected animals were Ngong 22, Maiden 65, Lucy 19, Tembo 3, Betty and Ngong 17 among others. The problem may persist due to the delayed treatment. Also the rotational employment of casual workers as animal health technicians, lead unclear and improper treatment records and hence problematic detection of mastitis. Lack of supply of detergents and use of few towels for all milking animals is the cause of the spread of infection among animals.

The routine usage of the strip cup to check for clinical mastitis should be augmented by CMT checks for all milking cows. Continuous testing of cultures for antibiotic susceptibility outline will be beneficial for selection of an appropriate antibiotic and as well identify the changing drifts of antibiotics resistance for developing antibiotic use approach (Hossain et al., 2017).Most drugs used on the farm are Terrexine, Intramammary tubes (multi-ject) Adamycin, Penstrep, and Neomycin. The farm does not practice dry cow therapy and this may exacerbate the $10 \%$ positive incidences of mastitis observed.

\section{Recommendation and Control}

The most effective method for the prevention of mastitis is through the establishment of good husbandry practices, sanitation, sound milking procedures, including post-milking, teat dipping and treatment during the nonlactating period and culling of chronically infected cows. Rotational use of the most effective drugs to treat mastitis infections, such as; Tetracycline, Gentamycin, Enrofloxacin, Sulfamethoxazole, Ceftifour and Streptomycin is advised.

The recommended control measures include: Maintaining clean and dry cow environment as much as possible; observing high standards of hygienic milking procedures, hand and machine - proper vacuum levels i.e. $40-50 \mathrm{kPa}$ and pulsations $56-60 \mathrm{P} /$ minute; as well as having routine dry cow therapy/ post-milking intramammary infusion with effective germicidal agents.

The specific causative agents were; Staphylococcus aureus, Streptococcus agalacteae, and E. coli. The drug of choice for the above causative agents as per the sensitivity results were; Tetracycline, Gentamycin, Enrofloxacin, Sulfamethoxazole, Ceftifour and Streptomycin.

The incidence rate of mastitis in Tatton Agriculture Park stands at $82.9 \%$. The CMT reagent is not a fully reliable test for detection of sub-clinical mastitis cases, therefore, should be accompanied by a bacteriological test for accurate diagnosis. The most efficient way for the prevention of mastitis is through the formation of noble husbandry practices, hygiene, comprehensive milking procedures, intervention during throughout the nonlactating period and removing of persistently septic cows in the herd.

\section{Acknowledgment}

We wish to acknowledge with gratitude the financial assistance offered by the Department of Animal Sciences in support of this project and laboratory technicians and the Manager TAP for logistics.

\section{References}

Aghamohammadi, M., Haine, D., Kelton, D.F., Barkema, H.W., Hogeveen, H., Keefe, G.P., and Dufour, S. 2018. HerdLevel Mastitis-Associated Costs on Canadian Dairy Farms. Front Vet Sci. 2018 May 14; 5: 100. doi: 
10.3389/fvets.2018.00100. eCollection 2018. PMID: 29868620.

Black, J.G., and Black, L.J. 1999. Microbiology: Principles and Explorations, 9th Edition. ISBN: 978-1118-74316-4. Aug 2015960 pages.

Current concepts of Bovine mastitis. 1996. National Mastitis council.

El-Hamid, M.I.A. 2016. Bovine Mastitis: Current Concepts and Future Control Approaches. Austin Clin. Microbiol., 12: 1007.

FAO, 2014. Impact of mastitis in small-scale dairy production systems. Animal Production and Health Working Paper. No. 13. Rome.

Fernandes, Dos Santos, F., Mendonça, L.C, Reis, D.R.L, Guimarães, A.S, Lange, C.C., Ribeiro, J.B., Machado, M.A., and Brito, M.A.V.P. 2016.Presence of mecA-positive multidrug-resistant Staphylococcus epidermidis in bovine milk samples in Brazil. J Dairy Sci. 2016 Feb; 99(2):1374-1382. doi: 10.3168/jds.2015-9931. Epub 2015 Dec 17. PMID: 26709182.

Gomes, F., and Henriques, M. 2016. Control of Bovine Mastitis: Old and Recent Therapeutic CurrMicrobiol.72: 377-382.

Hogeveen, H., and Van Der Voort, M. 2017.Assessing the economic impact of an endemic disease: the case of mastitis. Rev Sci Tech. 2017 Apr; 36(1):217226. doi: 10.20506/rst.36.1.2623. Review. PMID: 28926014.

Hossain, M., Paul, S., Hossain, M., Islam and Alam. 2017. Bovine Mastitis and Its Therapeutic Strategy Doing Antibiotic Sensitivity Test. Austin J Vet Sci \& Anim Husb. Austin J Vet Sci \& Anim Husb, 4(4), 1030-1031.

James Ombiro Ondiek, Ogore, P.B, Shakala, E.K and Kaburu, G.M. 2013.Prevalence of bovine mastitis, its therapeutics and control in Tatton Agriculture Park,
Egerton University, Njoro District of Kenya. Basic Research Journal of Agricultural Science and Review ISSN 2315-6880 Vol. 2(1) pp. 15-20 January 2013. Available online http//www. basic researchjournals.org.

Karimuribo, E, D, Fitzpatrick, J. L, Bell, C, E, Swai, E, S, Kambarage, D, M, Ogden, N, H and French, N. P. 2006. Clinical and subclinical mastitis in smallholder dairy farms in Tanzania: Risk, intervention and knowledge transfer. Preventive Veterinary Medicine, 74(1), 84-98. DOI: 10.1016/j.prevetmed. 2006.01.009.

Karthikeyan, A. 2003. Clinicopathological and ultrasonographic studies in bovine mastitis. M.V.Sc., Thesis submitted to Tamilnadu Veterinary and Animal Sciences University, Chennai, India.

Mugambi, D.K., Maina, M.W., Kairu, S., and Gitunu, A.M.M. 2015. Assessment of performance of smallholder dairy farms in Kenya: an econometric approach. Journal of Applied Biosciences, 85:7891- 7899 .

Muia J.M.K, Kariuki, J.N, Mbugua, P.N, Gachuiri C.K, Lukibisi, L.B, Ayako, W.O., and Ngunjiri, W.V. 2011. Smallholder dairy production in high altitude Nyandarua milk-shed in Kenya: Status, challenges and opportunities. Livestock Research for Rural Development, Volume 23, Article \#108 Retrieved March 23, 2017, from http://www.lrrd.org/lrrd23/5/muia23108 .htm.

Nunes, S.F., Bexiga, R., Cavaco, L.M, Vilela, C.L. 2007. Technical note: Antimicrobial susceptibility of Portuguese isolates of Staphylococcus aureus and Staphylococcus epidermidis in subclinical bovine mastitis. J Dairy Sci. 2007 Jul; 90(7):3242-6. PubMed PMID: 17582107. 
Odero-Waitituh, J.A. 2017.Smallholder dairy production in Kenya; a review. Livestock Research for Rural Development. Volume 29, Article \#139.Retrieved August 6, 2018, from http://www.lrrd.org/lrrd29/7/atiw29139. html.

Oliver, S.P., and Murinda, S.E. 2012. Antimicrobial resistance of mastitis pathogens. Vet Clin North Am Food Anim Pract. 2012 Jul; 28(2):165-85. doi: 10.1016/j.cvfa.2012.03.005. Epub 2012 Apr 28. Review. PubMed PMID: 22664201.

Oliveira, L., Langoni, H., Hulland C, Ruegg, P.L. 2012. Minimum inhibitory concentrations of Staphylococcus aureus recovered from clinical and subclinical cases of bovine mastitis. J Dairy Sci. 2012 Apr; 95(4):1913-20. doi: $\quad$ 10.3168/jds.2011-4938. PubMedPMID: 22459838.

Omore, A.O, Muriuki, H., Kinyanjui, M., Owango, M., and Staal, S. 1999. The Kenya Dairy sub-sector: A rapid appraisal. Research report of the MoLFD/ KARI/ ILRI. Smallholder dairy (Research and Development) project. International research institute. Nairobi Kenya. 51pp.

Ondiek, J.O, Ogore, P.B., and Kemboi, F. 2018. Clinical Mastitis Gives OffFlavor and Reduces Quality of Milk in Smallholder Goat Farms https://doi.org/ 10.20546/ijcmas.2018.701.287; http:// www.ijcmas.com.

Peeler, E.J., and Omore, A. 1997.Manual of livestock Production Systems in Kenya. 2nd Edition. Retrieved March 23, 2017, from http://www.fao.org/docrep/article/ agrippa/557_en.htm.

Philpot, W.N., and S.C, Nickerson, 2000. Winning the Fight Against Mastitis. Westfalia Surge, Naperville, USA.

Saini, V., McClure, J.T., Scholl, D.T., DeVries, T.J., Barkema, H.W. 2012.
Herd-level association between antimicrobial use and antimicrobial resistance in bovine mastitis Staphylococcus aureus isolates on Canadian dairy farms. J Dairy Sci. 2012. Apr; 95(4):1921-9. doi: 10.3168/jds.2011-5065. PubMed PMID: 22459839.

Saini, V., McClure J.T., Scholl, D.T., DeVries, T.J., Barkema, H.W. 2013. Herd-level relationship between antimicrobial use and presence or absence of antimicrobial resistance in gram-negative bovine mastitis pathogens on Canadian dairy farms. J. Dairy Sci. 2013 Aug; 96(8):4965-76. doi: 10.3168/jds.2012-5713. Epub 2013 Jun 13. PubMed PMID: 23769367.

Schalm, O.W., Carroll, E.J., and Jain, N.C. 1971. Bovine mastitis. Laboratory Handbook on Bovine Mastitis" 1999 National Mastitis Council, Inc. Madison, WI 1971 Edn. Lea and Febiger, Philadelphia, USA.

Sharma, P.A., Chhabra, R. and Sindhu, N. 2012. Prevalence of sub clinical mastitis in cows: its etiology and antibiogram. Indian J Anim. Res. 46 (4): 348 - 353, 2012.

Technoserve, 2008. The dairy value chain in Kenya. Project report East African Dairy Development Programme. Retrieved March 23, 2017, from https://cgspace.cgiar.org/bitstream/hand le/10568/2407/Dairy\%20Value\%20Cha in\%20Kenya\%20Report.pdf;jsessionid= 7FA19AD78BB4160F4443BB7321A49 ?sequence $=1$.

Rollin, E., Dhuyvetter, K.C., and Overton, M.W. 2015.The cost of clinical mastitis in the first 30 days of lactation: An economic modeling tool. Preventive Veterinary Medicine, 122(3), 257-264. https://doi.org/10.1016/j.prevetmed.201 5.11.006. 
Radostits, O.M., Gay, C.C., Blood, B.C and Hinchcliff, K.W. 2000.Veterinary medicine A textbook of the diseases of cattle, sheep, pig, goat and horses, 9thEdn., WB Saunders.

USAID (United States Aid for International Development) and GoK (Government of Kenya). 2009. Dairy value chain competitive assessment and action plan development. Final report. Pp: 1-21.

Van Soest, F.J.S., Santman-Berends, I.M.G.A., Lam, T.J.G.M., and Hogeveen, H. 2016. Failure and preventive costs of mastitis on Dutch dairy farms. J Dairy Sci. 2016. Oct; 99(10):8365-8374. doi: 10.3168/jds. 2015-10561. Epub 2016 Jul 27. PubMed PMID: 27474980.
Wilson, D.J., González, R.N., and Sears, P.M. 1995. Segregation or use of separate milking units for cows infected with Staphylococcus aureus: Effects on prevalence of infection and bulk tank somatic cell count. J. Dairy Sci.78:2083-2085.

Yoshimura, H., Ishimaru, M., Kojima, A. 2002. Minimum inhibitory concentrations of 20 antimicrobial agents against Staphylococcus aureus isolated from bovine intramammary infections in Japan. J Vet Med B Infect Dis Vet Public Health. 2002 Nov; 49(9):457-60. PMID: 12489715.

\section{How to cite this article:}

Ondiek, J.O. and Kemboi, F. 2018. Bovine Mastitis Prevalence, Aetiology, Therapeutics and Control in Tatton Agriculture Park, Egerton University. Int.J.Curr.Microbiol.App.Sci. 7(09): 3417-3426. doi: https://doi.org/10.20546/ijcmas.2018.709.424 